\title{
3
}

\section{Entre a tradição e inovação da prática profissional do psicólogo: considerações sobre atuação dos egressos da Universidade Federal de Santa Catarina - Brasil}

Entre la tradición e innovación de la práctica profesional del psicólogo: consideraciones sobre la actuación de los egresados de la Universidad Federal de Santa Catarina - Brasil

Between tradition and innovation in the professional practice of the psychologist: considerations about the performance of the graduates from Federal University of Santa Catarina - Brazil

Valéria De Bettio Mattos ${ }^{1}$

Gabriela Amâncio de Souza?

$1 \quad$ Professora do departamento de Psicologia da Universidade Federal de Santa Catarina [Brasil]. E-mail: valeria.mattos@ufsc.br.

2 Pesquisadora do Programa Institucional de Iniciação Científica e Tecnológica vinculado ao Conselho Nacional de Desenvolvimento Científico e Tecnológico. E-mail: gabi amancio8@hotmail.com 


\section{RESUMO}

Este artigo resulta de uma pesquisa desenvolvida junto aos egressos do curso de psicologia formados na Universidade Federal de Santa Catarina [UFSC] no período de 2010 a 2017. 0 intuito do artigo é analisar componentes relacionados à caracterização do[s] vínculo[s] empregatícios dos egressos que se encontram atualmente empregados, sejam em instituições públicas ou privadas. Além disso, optou-se nesta análise apenas pelos egressos que recebem formalmente remuneração o que configura uma derivação da pesquisa maior por ser composta apenas por aqueles que trabalham na área, totalizando 78 egressos, o que representa $34 \%$ dos 228 psicólogos formados no período. Trata-se de investigação descritiva com finalidade exploratória, de natureza quanti-qualitativa. Utilizou-se um questionário online com perguntas fechadas e abertas e recorreu-se à análise dos condicionantes macro e microssociais envolvidos na trajetória dos egressos para que fosse possivel entender a dinâmica de suas carreiras em construção. Para realizar a análise do percurso profissional desses egressos, investigou-se a diversificação das atuações, seja no repertório de atividades realizadas ou no tipo e local de trabalho. A remuneração média dos egressos concentra-se na faixa que varia entre três e cinco salários mínimos [38,8\%], sendo que o setor público aparece como o maior empregador [41,4\%]. Grande parte dos egressos possui jornadas de trabalho semanais que variam entre 31 e 40 horas [33,8\%] e costumam trabalhar na modalidade individual [31\%] e/ou em equipes multidisciplinares [31\%], muitas vezes ocorrendo concomitantemente. A maioria relata encontrar realização profissional, variando entre estar satisfeito [43,8\%] e muito satisfeito [23,8\%] no trabalho. Os dados indicam que o crescente assalariamento da profissão é marcado consequentemente pela diversidade de setores nos quais o psicólogo pode atuar, o que sugere novos horizontes para a atuação desses profissionais.

\section{PALAVRAS-CHAVE}

Egressos; trajetória profissional; psicologia. 


\title{
RESUMEN
}

Este artículo resulta de una investigación desarrollada junto a los egresados del curso de psicología de la Universidad Federal de Santa Catarina (UFSC] del año 2010 al 2017. El propósito del artículo es analizar componentes relacionados a la caracterización del[los] vínculo[s] de los egresados que se encuentran actualmente empleados, ya sea en instituciones públicas o privadas. Además, se optó en este análisis sólo por los egresados que reciben formalmente remuneración, lo que configura una derivación de la investigación mayor al ser compuesta sólo por aquellos que trabajan en el área, totalizando 78 egresados, lo que representa el 34\% de los 228 psicólogos formados en el período. Se trata de una investigación descriptiva con fines exploratorios, de naturaleza cuantitativa. Se utilizó un cuestionario online con preguntas cerradas y abiertas y se recurrió al análisis de los condicionantes macro y microsociales involucrados en la trayectoria de los egresados para entender la dinámica de sus carreras en construcción. Para realizar el análisis del recorrido profesional de estos egresados, se investigó la diversificación de las actuaciones, sea el repertorio de actividades realizadas o el tipo y lugar de trabajo. La remuneración media de los egresados se concentra en la franja entre tres y cinco salarios mínimos [38,8\%], y el sector público aparece como el mayor empleador [41,4\%]. Los egresados tienen jornadas de trabajo semanales que varían entre 31 y 40 horas [33,8\%] y suelen trabajar en la modalidad individual [31\%] y/o en equipos multidisciplinarios [31\%], a menudo concomitantemente. La mayoría relata encontrar realización profesional, variando entre estar satisfecho $[43,8 \%$ y muy satisfecho $[23,8 \%]$ con el trabajo. Los datos indican que el creciente asalariamiento de la profesión es marcado consecuentemente por la diversidad de sectores en los que el psicólogo puede actuar, lo que sugiere nuevos horizontes para la actuación de esos profesionales.

\section{PALABRAS CLAVE}

Egresados; trayectoria profesional; psicología.

\begin{abstract}
This article is a result from a research developed with graduates of the Psychology formed at Federal University of Santa Catarina [UFSC] from 2010 to 2017. The purpose of this article is to analyze components related to the characterization of employment bond[s] from the graduates who are currently employed, whether in public or private institutions. Furthermore, it was chosen for this analysis only the students that were receiving formally remuneration, which constitutes a derivation of a bigger research, composed only by those who work in the area, totaling 78 graduates, which represents 34\% of the 228 psychologists formed in the period. It is a descriptive research with an exploratory purpose and a quantitative-qualitative nature. An online questionnaire was used with closed and opened questions, and an analysis was made of the macro and microsocial conditioning involved in the trajectory of the graduates, so it was possible to understand the dynamics of their careers in progress. To perform the professional analysis of these graduates, was investigated the diversification of their performances, took it in the repertoire of activities carried out or in the type and place of work. The average salary of graduates is between 3 and 5 minimum salaries [38.8\%], being that the public sector is the largest employer [41.4\%]. Most of the graduates have weekly workdays ranging from 31 to 40 hours [33.8\%] and usually works in the individual mode [31\%] and/or in multidisciplinary teams [31\%], frequently occurring concomitantly. Most report finding professional achievement varying from being satisfied [43.8\%] and very satisfied [23.8\%] at work. The data suggest that the increased wage of the profession is marked by the diversity of sectors in which the psychologist can act, suggesting new horizons for these professionals.
\end{abstract}

\section{KEYWORDS}

Graduates, professional trajectory, psychology. 


\section{Introdução}

O conceito de carreira é amplo, uma vez que a busca por sua compreensão perpassa complexas estruturas individuais, organizacionais e sociais, carecendo de amparo nos fundamentos da Psicologia, da Sociologia e da Administração [Bendassolli, 2009). Na medida em que as sociedades se desenvolvem, as carreiras, tanto para indivíduos quanto para as organizações, adquirem novas formas, estruturas e configurações, gerados a partir de mudanças econômicas, sociais e culturais.

No que se refere à carreira do psicólogo atualmente, percebe-se uma pluralidade de áreas com diferentes especializações e possibilidades de inserção em diversas instituições públicas e privadas, como hospitais, escolas, consultórios, empresas, além do âmbito jurídico [Conselho Federal de Psicologia, 1998; Malvezzi, Souza, \& Zanelli, 2010). Ser psicólogo no Brasil é estar atuando em uma profissão que fornece diversas possibilidades de inserção profissional, o que facilita as alternativas de carreira para os jovens recém-formados da área (Malvezzi et al. 2010]. 0 fim da graduação universitária é marcado pelo início de uma nova etapa: o exercício da profissão. Esta traz implicações para a transição universidade/trabalho, envolve o mercado laboral e o início da construção da carreira dentro da profissão, contexto que será explorado no presente artigo.

A temática apresenta relevância científica e social, a partir do conhecimento sobre a realidade profissional dos egressos do curso de Psicologia da Universidade Federal de Santa Catarina, pois possibilitará uma reflexão acerca da formação recebida e sua relação com o mercado de trabalho ${ }^{3}$. A pesquisa baseou-se na busca exploratória de localizar os egressos e conhecer sua prática profissional, bem como as principais características envolvidas nos trabalhos por eles desenvolvidos. A graduação pode ser entendida como um dos principais meios de ligação entre o indivíduo e sua inserção como profissional em determinada área. Portanto, a realização desta pesquisa é justificada porque tem se tornado fundamental estudar a relação entre a trajetória acadêmica e a realidade no campo de trabalho dos egressos do ensino superior. Além disso, existem diretrizes de formação básica do psicólogo que preconizam competências essenciais destacadas nas Diretrizes Curriculares Nacionais, instituídas pelo Conselho Nacional de Educação [Brasil, 2004; Brasil, 2011]), as quais complementam características atitudinais e comportamentais necessárias para desenvolver um bom trabalho com outros indivíduos, que são os principais beneficiários dos serviços fornecidos pelos psicólogos.

0 artigo busca fazer uma análise referente à atuação e trajetória profissional de $78^{4}$ egressos formados no curso de Psicologia na Universidade Federal de Santa Catarina [UFSC] entre 2010 e 2017, o que possibilita conhecer parcialmente a realidade atual do trabalho e da inserção no

3 Para contextualizar, o curso de Psicologia na UFSC é oferecido em tempo integral, com carga horária de 4080 horas [formação psicólogo]. O currículo contempla atividades de ensino, pesquisa e extensão que se alinham a quatro áreas/ênfases: saúde e processos clínicos; organizacional e do trabalho; escolar e educacional e processos comunitárias e ações coletivas. A formação inicial tem duração mínima de cinco anos para a habilitação profissional de bacharel e mais um ano e meio para aqueles que desejarem agregar a habilitação de licenciado.

$4 \quad 0$ número de participantes da pesquisa é de 103, porém apenas 78 informaram estar trabalhando no momento da aplicação do questionário. Portanto, a presente amostra é uma derivação da pesquisa maior, por ser composta por aqueles que atualmente encontram-se empregados, o que representa 34\% da população de egressos formados entre 2010 e 2017. 
mercado de trabalho dos psicólogos formados nesta instituição. O intuito da pesquisa é analisar componentes relacionados à vinculação trabalhista dos egressos que se encontram atualmente empregados, sejam estes espaços públicos e/ou privados. Além disso, optou-se por considerar na análise apenas os egressos que se encontram trabalhando com remuneração.

0 presente artigo se constitui a partir de um recorte de dados originalmente extraídos de um formulário cadastrado em uma plataforma online, no qual foram elencadas diversas perguntas relacionadas à trajetória profissional e acadêmica dos egressos do curso de Psicologia da referida instituição.

Para realizar a análise da trajetória profissional desses egressos, fez-se necessário articular seu processo formativo inicial com seu emprego atual. É necessário destacar que recorreu-se à análise dos condicionantes macro e microssociais envolvidos na vida dos egressos para que fosse possivel entender a dinâmica da carreira que está em construção. Mesmo com o crescimento das possibilidades de atuação do psicólogo para outras áreas que não as clássicas, a atuação clínica continua sendo vista por uma grande parcela da população como área de atuação mais tradicional. Porém, através dos dados aqui trazidos e de outras pesquisas nacionais realizadas [Bastos, 1988; Bastos, Gondim e Borges-Andrade, 2010; Macêdo, Heloani e Cassiolato, 2010; Malvezzi et al. 2010], percebe-se que a clínica tradicional já não tem mais a maior inserção no mercado de trabalho.

Isso ocorreu devido ao crescimento de uma representação mais diversificada do trabalho do psicólogo, aos avanços teóricos, as mudanças de mercado, aos aspectos políticos, além do advento do campo da saúde pública, que delineou um novo cenário para a carreira dos psicólogos na última década, o que ampliou os espaços de inserção desse profissional no mercado de trabalho. Nesse contexto, tanto a profissão, por meio de seu órgão de classe, quanto a sociedade necessitaram desenvolver alternativas para viabilizar a inserção profissional de forma segura e duradoura, bem como a extensão do serviço psicológico a grupos minoritários e de baixa renda.

\section{Fundamentação teórica}

A inserção profissional pode ser definida como a passagem de um curso universitário para 0 mercado de trabalho [Callegari, 2001]. Esse processo transicional é complexo e envolve aspectos externos e internos, desde demandas do mercado de trabalho, situação socioeconômica do país, exigências profissionais, processos de formação e até mesmo características pessoais de cada indivíduo.

De acordo com o estudo de Callegari [2001], a inserção profissional está relacionada a uma rede de variáveis referentes à percepção que os egressos têm de si mesmos e da profissão. A referida autora verificou que os egressos necessitavam prolongar seus estudos através de pós-graduações/especializações com o intuito de conseguir maiores possibilidades dentro do mercado de trabalho. Tal dado vai ao encontro da pesquisa de Mattos e Rodrigues [2018] no sentido de constatar que os egressos do curso de psicologia da instituição investigada buscam especializações em sua área de formação e acabam por conseguir ampliar as possibilidades de inserção profissional.

De acordo com Malvezzi, Souza e Zanelli [2010], é através da inserção profissional que os 
indivíduos conquistam seu espaço social, adquirem experiências e conhecimentos necessários para percorrer um itinerário profissional e desenvolver sua identidade psicossocial. É por meio do trabalho que conseguem condições materiais para sobrevivência e para alcançar o bem-estar que desejam, mas, também, satisfação pessoal, mediada pela experiência laboral (Martinez \& Paraguay, 2003].

Bendassolli [2009] afirma que a primeira contribuição da psicologia ao estudo das carreiras dá ênfase à singularidade e natureza interpretativa do sujeito, diferindo de antigos modelos que interpretavam carreira como um processo resultante apenas de escolhas e trajetórias pessoais, sem considerar o contexto histórico e cultural no qual o sujeito está inserido. A segunda contribuição dos estudos associa-se à tradição da psicologia vocacional, que procura explicar o processo de desenvolvimento pessoal e profissional com ênfase na relação entre indivíduo, trabalho e carreira. Por fim, a terceira liga-se à noção de socialização e construção da identidade através do contexto do trabalho.

Levando em consideração as contribuições da psicologia trazidas por Bendassolli [2009], faz-se necessário enfatizar que as carreiras contemporâneas precisam considerar diversas mudanças ocorridas no mercado de trabalho como, por exemplo, globalização, evolução das tecnologias, flexibilidade, instabilidade e crises econômicas. Tais mudanças resultam em alterações no modo de construir as carreiras e trilhar o caminho profissional [Bendassolli, 2009]. A instabilidade do atual mercado favorece o aumento da insegurança dos profissionais, em especial daqueles que estão entrando no mercado de trabalho, como é o caso de jovens egressos do ensino superior. Posto isto, é possivel pensar que tais fatores podem dificultar a inserção profissional desses recém-formados, tornando fundamental conhecer a realidade deste público para então propor formas de intervenção (Malvezzi et. al, 2010).

Gondim, Bastos e Peixoto [2010] apontam que o conhecimento e a reflexão crítica sobre questões que regem a inserção no mundo do trabalho na atualidade tornam-se imprescindiveis nas práticas da formação universitária e no planejamento de carreira. Abbad e Mourão [2010] alertam que a formação universitária deve considerar o contexto histórico, cultural e social que se apresenta diferenciado na vida de cada um dos indivíduos. Com isso, não se pode limitar o processo de inserção profissional a algo inteiramente econômico; é necessário articular esse fator com as vivências e experiências resultantes das interações do indivíduo no contexto social em que se insere.

A formação e atuação dos psicólogos no Brasil têm sido objeto de estudos e discussões ao longo dos anos e isto vem ocorrendo desde a regulamentação da profissão no país em 1962. Essas discussões incidem sobre a função social da Psicologia e a sua interface junto às demais áreas do conhecimento; a necessidade de diversificação teórica e de flexibilização do currículo e, após a formação, analisar as trajetórias profissionais desenvolvidas. Essas perspectivas constituem-se como desafios para o desenvolvimento das competências exigidas na formação profissional em Psicologia [Bastos \& Gondim, 2010].

Na formação de Psicologia existia uma forte concentração nos contextos da clínica, da escola e das organizações, e com isso, de forma geral, os profissionais tendem a generalizar o modelo clínico hegemônico para outras áreas e contextos de atuação, o que gera dificuldades (Dimenstein, 2000]. Ainda que as possibilidades de atuação do psicólogo tenham sido ampliadas, a Psicologia clínica continua sendo vista, tanto pelas pessoas leigas quanto pelos próprios profissionais ou 
recém-formados, como a área de atuação mais tradicional e aquela com maior possibilidade de inserção [Bastos e Gomide, 2010].

As competências esperadas na formação do psicólogo são destacadas nas Diretrizes Curriculares Nacionais, instituídas pelo Conselho Nacional de Educação [Brasil, 2004; Brasil, 2011), a partir de uma formação voltada para a atuação profissional, para a pesquisa e para o ensino de Psicologia. A formação básica deve aprofundar as competências e habilidades que são centrais e indispensáveis ao psicólogo, tais como: atenção à saúde, tomada de decisões, possuir conduta pautada em evidências científicas, comunicação, liderança, administração e gerenciamento, além de educação permanente [Brasil, 2011]. As DCNs para os cursos de Psicologia, como projeto de mudança, podem causar espanto às estruturas de muitos cursos, departamentos e universidades justamente por trazerem maior integração e diversidade na formação. Por outro lado, oferecem uma grande oportunidade de reforma e novas visões para o ensino-aprendizagem nos currículos de Psicologia.

Estas mudanças possibilitam uma inserção profissional diversificada entre os psicólogos, com atuações mais expressivas em áreas como psicologia da saúde [principalmente em instituições públicas vinculadas ao Sistema Único de Saúde - SUS e o Sistema Único de Assistência Social - SUAS ${ }^{5}$, do esporte, jurídica, entre outras, o que ampliou os espaços de atuação no mercado de trabalho (Malvezzi et al. 2010). Dessa forma, é possivel afirmar que os cursos de Psicologia precisam oferecer uma formação mais ampla para abarcar conhecimentos sobre as áreas emergentes em Psicologia e oportunizar atuações em contextos diferenciados de intervenção, pesquisa e docência. De acordo com Gondim [2002], uma formação generalista e a ampliação de experiências práticas durante o curso superior são fortes alternativas para atender à exigência de um perfil multiprofissional e proporcionar a maturidade pessoal e a identidade profissional necessárias para agir em situações de imprevisibilidade.

A partir da revisão de literatura, foram encontradas poucas pesquisas realizadas especificamente com egressos, sendo que estas ora centram esforços em analisar a realidade de determinadas instituições em locais específicos no país, ora têm a finalidade de conhecer melhor a categoria de psicólogos do país e de regiões, suas necessidades diante do mercado de trabalho e a avaliação que fazem sobre a formação que tiveram, áreas de interesse na Psicologia, entre outras características. [Conselho Federal de Psicologia, 1998; Bastos e Gomide, 2010; Malvezzi, Souza e Zanelli, 2010; Bastos, Gondim e Borges-Andrade, 2010).

Conhece-se pouco a respeito dos egressos dos cursos de graduação em diferentes áreas de formação e, sobretudo, sobre egressos de cursos de Psicologia, seja em termos das atividades profissionais que desenvolvem, seja em termos de cursos ou formas de continuidade dos estudos que buscam depois da graduação. Existem pesquisas nacionais sobre formação do profissional de psicologia no nível de graduação, porém são escassas as informações sobre estratégias de

5 Mattos e Rodrigues [2018] ressaltam que os dados desta pesquisa anunciam mudanças recentes na atuação profissional, fortemente impulsionadas por políticas públicas no campo da saúde e assistência social. É possível visualizá-las, por exemplo, nas ações de estágio e extensão vinculadas à psicologia social em espaços impulsionados pelo SUAS e também por formações complementares no nível de pós-graduação voltadas para atenção à saúde integral, direcionadas a uma clínica ampliada, transdisciplinar, visíveis na residência em hospitais Saúde Mental e Atenção Primária - bem como as políticas de formação em saúde pública, fortemente alavancadas pelo SUS, atuações estas não relatadas em pesquisa nacional realizada por Bastos \& Gondim [2010]. 
qualificação e requalificação utilizadas pelo psicólogo brasileiro após inserção no mercado de trabalho [Abbad e Mourão, 2010].

Esta escassez de estudos com egressos do ensino superior brasileiro não permite uma comparação entre os perfis profissional e educacional do aluno de Psicologia da UFSC com aqueles de outras universidades e regiões do país. A partir da lacuna de informações sobre a situação particular dos psicólogos egressos de Santa Catarina, este estudo buscou conhecer a formação e as trajetórias de trabalho dos egressos da única instituição federal a oferecer este curso no estado, formados entre os anos de 2010 e 2017, a fim de fornecer mais subsídios sobre a suas vivências profissionais.

A partir do levantamento bibliográfico realizado, da argumentação conjunta dos trabalhos referidos e de outros que se propuseram a investigar egressos do ensino superior, sua inserção, área de atuação dos profissionais psicólogos e o modo como avaliam a formação recebida, será possível conhecer melhor esta categoria profissional, tal como pretende a seção seguinte deste artigo.

\section{A inserção profissional de egressos: resultados e discussão}

Dos 103 respondentes totais da pesquisa, 80 [82,4\%] estão trabalhando atualmente e 78 exercem trabalhos remunerados. A remuneração média dos egressos que atualmente se encontram empregados varia entre 3 e 5 salários mínimos [SM], o que representa 38,8\%. Diferente dos dados sobre egressos trazidos na pesquisa de Malvezzi, Souza e Zanelli [2010], onde 26,2\% da amostra total de psicólogos ganhava algo igual ou superior a 10 saláriosmínimos [SM] e 42,7\% não atingiam 5 SM, é possível perceber que os profissionais de psicologia formados pela UFSC nos últimos cinco anos já conseguiram atingir uma certa paridade salarial, tendo em vista que 66,3\% dos egressos se encontram na faixa salarial de 2-5 SM, 16,3\% estão na faixa acima de 5 SM, 15\% estão na faixa de 1-2 SM ${ }^{6}$ e apenas 2,5\% exercem atividades não remuneradas, como é possível verificar no gráfico abaixo.

Gráfico 1 - Médias salariais

\section{Caso exerça trabalho remunerado, qual a faixa de renda?}

Média:5 Desvio padrão: 5,51

Fonte: Elaborada pelas autoras

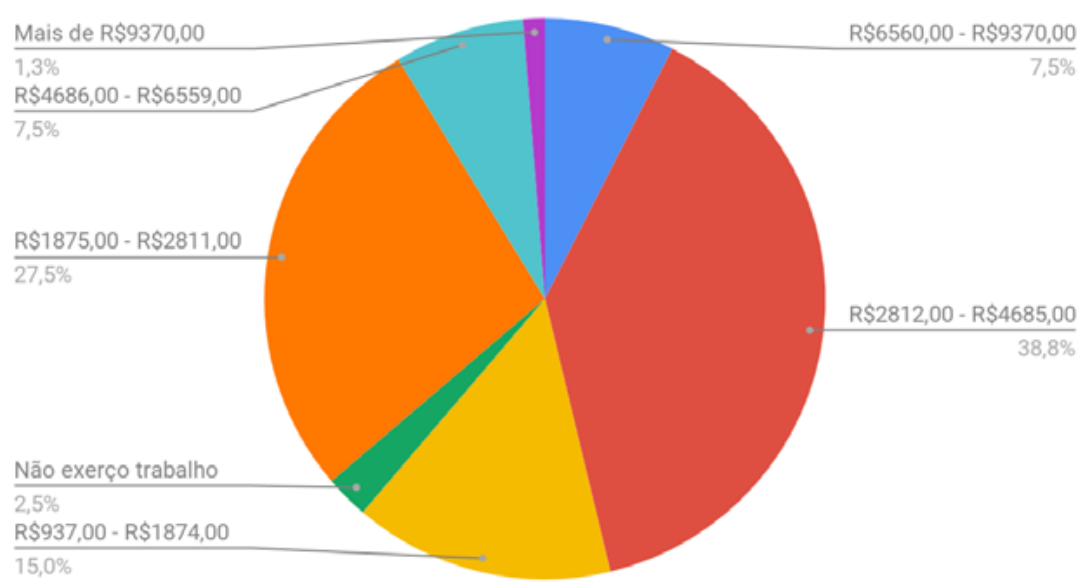

$6 \quad$ Osalário mínimo de 937 reais constante no gráfico era o valor correspondente ao ano de 2017, quando esta pesquisa foi iniciada. Todos os valores de referência foram pensados a partir desta cifra, ou seja, correspondentes a um número "x" de salários mínimos. Para fins de conversão, o valor anunciado corresponde atualmente a cerca de 215EUR. 
Cabe ressaltar que o trabalho assalariado do psicólogo se encontra acima da média recebida pela maioria dos brasileiros, que possuem o salário na faixa dos $R \$ 2205,00$ mensais, o que corresponde a ganhos que variam entre 1 a 2 SM [IBGE, 2018).

Uma constatação de grande importância obtida na pesquisa é o crescente assalariamento da profissão; o trabalho assalariado exercido pelos recém-formados aqui analisados é marcado consequentemente pela diversidade de setores nos quais o psicólogo pode atuar. Os dados revelam que existe um certo predomínio de inserção no serviço público [sejam em instituições federais, estaduais ou municipais], seguido pelo setor privado, sendo que o terceiro setor [instituições sem fins lucrativos/ONGs] não teve aparição significava nos dados dessa pesquisa, conforme aponta o gráfico a seguir:

\section{Gráfico 2 :}

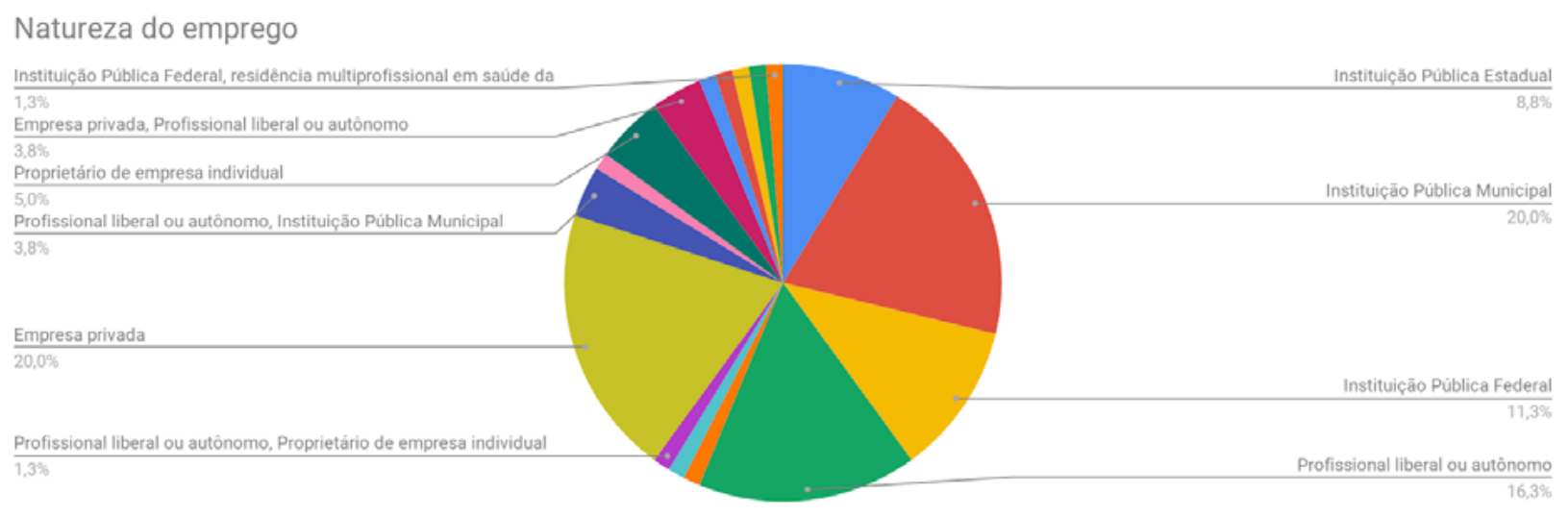

Média: 5 Desvio padrão: 5,51

Fonte: Elaborada pelas autoras

Com a finalidade de possuir uma renda em patamares razoáveis e que seja suficiente para sustentar a si e, às vezes, seus dependentes, os psicólogos já não conciliam tanto atividades autônomas e assalariadas, uma vez que poucos respondentes marcaram mais de uma opção, algo diferente do que acontecia na década de 1980 e foi mostrado por meio do levantamento nacional realizado pelo Conselho Federal de Psicologia [CFP], em 1988.

Bastos (1988) aponta que o fato de exercer dois ou mais empregos ao mesmo tempo poderia ser explicado pela fragilidade dos limites entre as áreas de atuação e a facilidade de movimentação entre elas. A variedade de oferta de trabalho, a insatisfação com a área de atuação e a baixa remuneração também poderiam explicar esta múltipla inserção. A atividade autônoma, que despontava de forma esmagadora nos levantamentos e pesquisas realizadas nos anos de 1980 como sendo a mais exercida pelos profissionais psicólogos, hoje ainda aparece de forma complementar ou como forma exclusiva de remuneração, porém em um número menos expressivo.

A título de exemplo, o levantamento realizado pelo CFP em 1988 mostrava que os assalariados representavam 51,9\% do total [37,9\% regime CLT; 8,2\% servidores públicos e 5,9\% com vínculo eventual] e os autônomos e os voluntários representavam 48,1\% [41,3\% autônomos e 6,7\% voluntários] [Bastos, Gondin e Borges-Andrade, 2010]. Assim como assinalado por Bastos 
[2010] sobre o levantamento nacional pouco mais de uma década antes, os dados recentes dos egressos de Psicologia da UFSC permitem dizer que a referência de um profissional liberal e autônomo não é hoje a principal forma de atuação dos psicólogos.

Em vista desses resultados, a profissão de psicólogo no Brasil caracteriza-se como um setor ocupacional amadurecido e em desenvolvimento (Malvezzi et.al 2010), ainda que seja uma profissão regulamentada há pouco mais de 50 anos. As pesquisas da última década mostram que existe uma significativa estabilidade em aspectos-chave da profissionalização trazidos devido aos trabalhos assalariados, em especial, os trabalhos em instituições públicas.

A clínica já não é mais o setor que concentra o maior número de psicólogos atuando. Assim como identificado por Bastos, Gondim e Andrade [2010] no levantamento nacional realizado sobre a profissão em 2008, os dados dos profissionais recém-formados da UFSC demonstram que novas áreas na psicologia vêm surgindo, como, por exemplo, social, hospitalar e jurídica, o que demonstra a consolidação de novos campos de atuação profissional.

Além disso, os dados desta pesquisa demonstram que o setor público aparece como o maior empregador na atualidade. As políticas sociais recentes como o SUS e o SUAS estão gerando importantes campos de trabalho para os psicólogos em todo o país, pois abrem espaço para profissionais da área em hospitais e outras unidades de saúde em diferentes níveis de atenção, como, por exemplo, Centro de Atenção Psicossocial [CAPS), Núcleo Ampliado de Saúde da Família [NASF] e Centro de Referência em Assistência Social [CRAS], o que pode explicar em certa medida essa maior representatividade dos psicólogos recém-formados atuando em setores públicos com um viés associado a práticas sociais e comunitárias.

A fim de ter uma compreensão mais detida da caracterização do trabalho desenvolvido pelos egressos da psicologia da UFSC, faz-se necessário analisar, para além do vínculo laboral, as especificidades da jornada de trabalho.

$\mathrm{Na}$ amostra analisada, a maioria dos egressos do curso que estão atualmente empregados possuem jornadas de trabalho semanais entre 31 a 40 horas [33,8\%], conforme evidencia 0 gráfico 3, seguidos por $25 \%$ que trabalham entre 21 e 30 horas por semana e $23,8 \%$ que realizam uma jornada laboral com mais de 40 horas semanais, de acordo com o gráfico a seguir.

\section{Carga horária semanal}

Gráfico 3- Cargas de trabalho

Média: 20 Desvio padrão: 5,35 Fonte: Elaborada pelas autoras

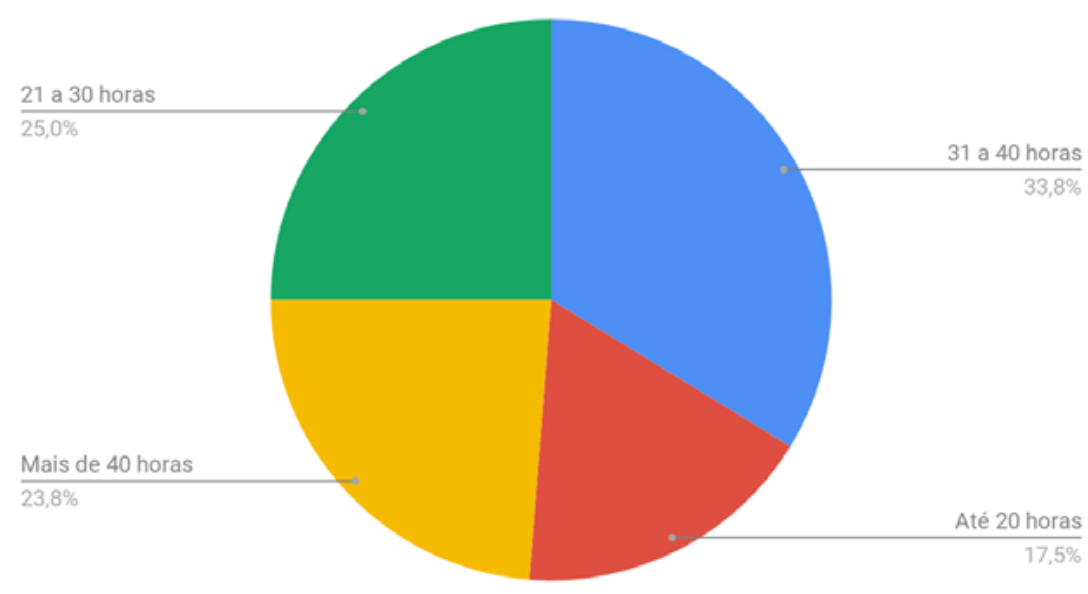


A pesquisa nacional realizada pelo CFP na década de 1980 apresentou resultados semelhantes; a carga horária semanal média mais elevada encontrava-se entre os trabalhadores empregados e os servidores estatutários, que atingiam em média 34 horas semanais. Já no trabalho autônomo a carga horária semanal média chegava a 14 horas e entre os psicólogos voluntários, a 10 horas semanais [Conselho Federal de Psicologia, 1988).

Pasqualli [1988] apontava, à luz dos dados trazidos pelo CFP à época, que a carga horária semanal média de trabalho dos psicólogos era visivelmente inferior à média das profissões em geral no país. Segundo dados do IBGE de 1985, 80,8\% dos trabalhadores brasileiros tinham carga de trabalho igual ou superior a 40 horas semanais.

Mais recentemente, Bastos \& Gomide [2010] advertem que essa diferença pode ser entendida por dois motivos: como um atributo do caráter feminino da profissão [a necessidade de possuir trabalhos de tempo parcial para assim poder assumir outras funções além da profissão de psicóloga] ou como uma imposição do mercado de trabalho, que impede que o profissional de psicologia combine trabalhos em locais e áreas diferentes para complementação dos seus rendimentos. Ademais, essas cargas horárias semanais de trabalho podem variar fortemente quando se consideram os vínculos de trabalho e os setores nos quais se inserem os psicólogos.

Quando se pensa a relação entre inserção dos psicólogos nos diferentes setores e carga horária semanal, um aspecto que deve ser levando em consideração é que o setor público é o único que mantém trabalhadores em regime de dedicação exclusiva, portanto contam com servidores cumprindo, em média, cargas de trabalho entre 30 e 40 horas semanais. Na pesquisa realizada por Macêdo, Heloani e Cassiolato [2010], o terceiro setor se destaca por ter a maior porcentagem [72,7\%] de psicólogos que trabalham até 20 horas semanais, já o setor privado também possui uma porcentagem elevada de profissionais que trabalham 20 horas semanais [45,6\%], superior, inclusive, ao de psicólogos que trabalham 40 horas [37,3\%]. Estes autores [op. cit.] também destacam que a marca do exercício profissional da Psicologia é a diversidade com que o profissional combina diferentes formas de inserção no mercado de trabalho. 52,7\% possuem mais de uma inserção, combinando atuações nos diferentes setores como o trabalho assalariado com o trabalho autônomo.

Para além da carga horário e regime de trabalho, pensar sobre os modelos de atuação profissional, seja individualizado ou compartilhado com diferentes profissionais, ajudam a compreender as habilidades requeridas pelos profissionais da área, na atuação multiprofissional, conforme aponta o gráfico 4.

\section{Modelos de atuação profissional}

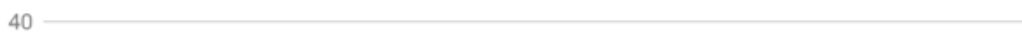

Gráfico 4:

Média: 23,5 Desvio padrão: 9 Fonte: Elaborada pelas autoras

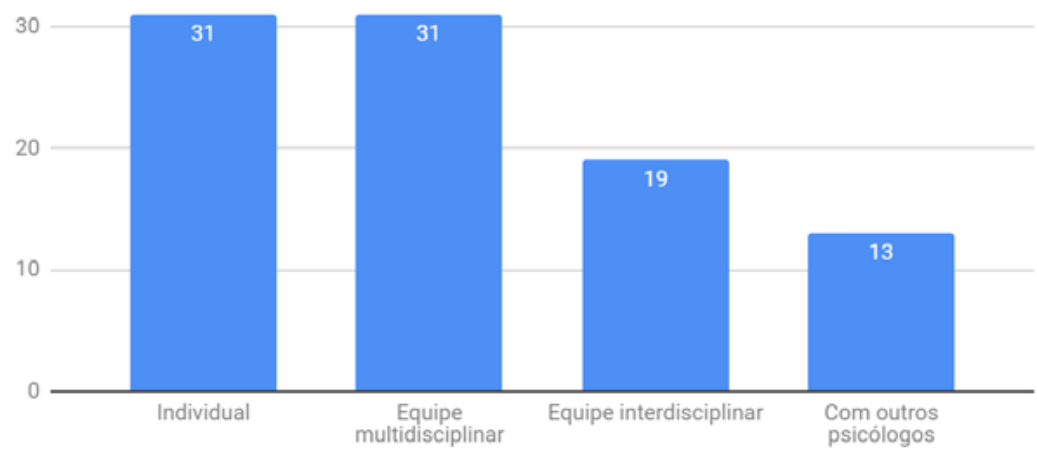


Referente aos modelos de atuação profissional, no momento de responder o questionário os egressos poderiam marcar mais de uma opção, caso fossem exercidas em sua atuação profissional. Portanto, o gráfico acima demonstra o número de vezes em que as opções foram marcadas pelos 78 respondentes que trabalham. Observa-se que o trabalho individual e a atuação em equipes multidisciplinares se destacam, com frequência de 31 respostas cada. Tal fato pode ser explicado pelo grande número de egressos do curso de Psicologia da UFSC estarem alocados em instituições públicas, nas quais as equipes são geralmente compostas por profissionais de diferentes áreas.

A inserção dos serviços de psicologia é privilegiada em instituições onde há espaço para a interação entre os diversos profissionais de uma equipe multidisciplinar, pois nestas ocasiões o psicólogo evidenciará a importância da valorização do conjunto dos aspectos comportamentais/ emocionais do[s] indivíduo[s] assistido[s].

Nesse sentido, a multidisciplinaridade pode ser considerada positiva, pois traz diversos olhares e visa auxiliar a compreender o indivíduo como um ser biopsicossocial, que está inserido em um contexto. Porém, ao mesmo tempo, existe o risco de fragmentação entre os olhares dos diferentes participantes da equipe e, consequentemente, a fragmentação da abordagem com o paciente/cliente quando não há um esforço coletivo de olhar o fenômeno na sua completude.

Quanto ao número de profissionais atuando de forma individual para a realização de análises dos processos intrapessoais e das relações interpessoais, possibilitando a compreensão do comportamento humano individual e de grupo no âmbito das instituições de várias naturezas, onde quer que se deem estas relações é necessário aplicar conhecimento teórico e técnico com o objetivo de identificar e intervir nos fatores determinantes das ações dos sujeitos, em sua história pessoal, familiar e social, vinculando-as também às condições políticas, históricas e culturais [Conselho Federal de Psicologia, 1992). Nesse sentido, procedimentos como aplicação de testes psicológicos e psicodiagnósticos são específicos da profissão, portanto, mesmo que o psicólogo atue em instituições com equipes multidisciplinares ou interdisciplinares, tais tarefas deverão ser realizadas pelo psicólogo.

Deve-se levar em consideração também a preocupação levantada por Botomé (1996]; Gil [1985]; Martín-Baró (1997] citados por Dimenstin [2000] a respeito do questionamento se a atividade que o psicólogo exerce no seu consultório particular contribui para que ele reproduza o modelo clínico de atendimento individualizado em contextos inapropriados para esse nível de intervenção.

Para Yamamoto e Oliveira [2010], essa indagação adquire sentido, embora a psicologia deva assumir o seu papel questionador e transformador do status quo, pois a prática profissional pode estar reproduzindo estruturas sociais e relações de poder na medida em que os psicólogos podem não compreender claramente quem é o real beneficiário do conhecimento e das intervenções que realizam na sua prática de trabalho.

A respeito das atuações individuais, é possível pensar que mesmo que a clínica individual ainda seja o principal fator envolvido na representação social do psicólogo, ela ainda é uma área de atuação restrita a determinados estratos socioeconômicos, dado seu caráter privatista e majoritariamente individualizante [Mattos e Rodrigues, 2018].

Portanto, de acordo com Bastos e Gomide [2010], para que se possa romper de forma efetiva o elitismo da profissão é necessário que medidas de amplo espectro passem pela formação 
dos novos profissionais e que a luta por políticas públicas para a área social privilegiem um atendimento global dos indivíduos e suas múltiplas necessidades. Passado uma década da pesquisa referenciada, os dados da investigação aqui apresentada sinalizam para uma abertura de outras formas de atuar, com público mais diversificado e menos elitizado, garantidas sobremaneira pelas políticas do SUS E SUAS.

Para tanto, é necessário que o psicólogo compreenda os aspectos mais amplos do contexto social em que vive. Nessa perspectiva, pressupõe que sua intervenção deve se iniciar com uma análise integral das contradições do trabalho dentro das condições dadas por seus processos de produção particulares [Sato, 2003; Sato, Bernardo, \& Oliveira, 2008). Com isso, um dos principais desafios do psicólogo consiste em deixar de lado a ideia de se pensar como autoridade única, dona de um conhecimento mítico sobre o outro. Cabe a esse profissional superar os esquemas que, muitas vezes, estão presentes na sua formação, abandonando posturas cômodas que prevalecem em seu exercício, discursos elitistas e práticas que estejam focadas apenas nos interesses dos mais privilegiados do ponto de vista financeiro.

Por fim, quando se analisa a qualidade da inserção profissional é de extrema relevância investigar o nível de satisfação no trabalho.

A satisfação no trabalho é um fenômeno psicossocial amplamente estudado devido à influência que pode exercer tanto no resultado do trabalho, manifesto em atitudes e comportamento profissional, quanto nos aspectos relacionados à saúde física e mental, com repercussões no plano social, na vida pessoal e familiar do indivíduo, bem como quanto nas organizações (Martinez \& Paraguay, 2003].

Nesse sentido, vale lembrar que o ambiente psicossocial, disposto no trabalho, engloba a organização e as relações sociais de trabalho. Por possuir uma diversidade de aspectos percebidos subjetivamente, sua conceituação pode variar entre os indivíduos ou na própria pessoa, de acordo com diferentes circunstâncias e ao longo do tempo.

Gráfico 5 - Grau de satisfação com o trabalho atual

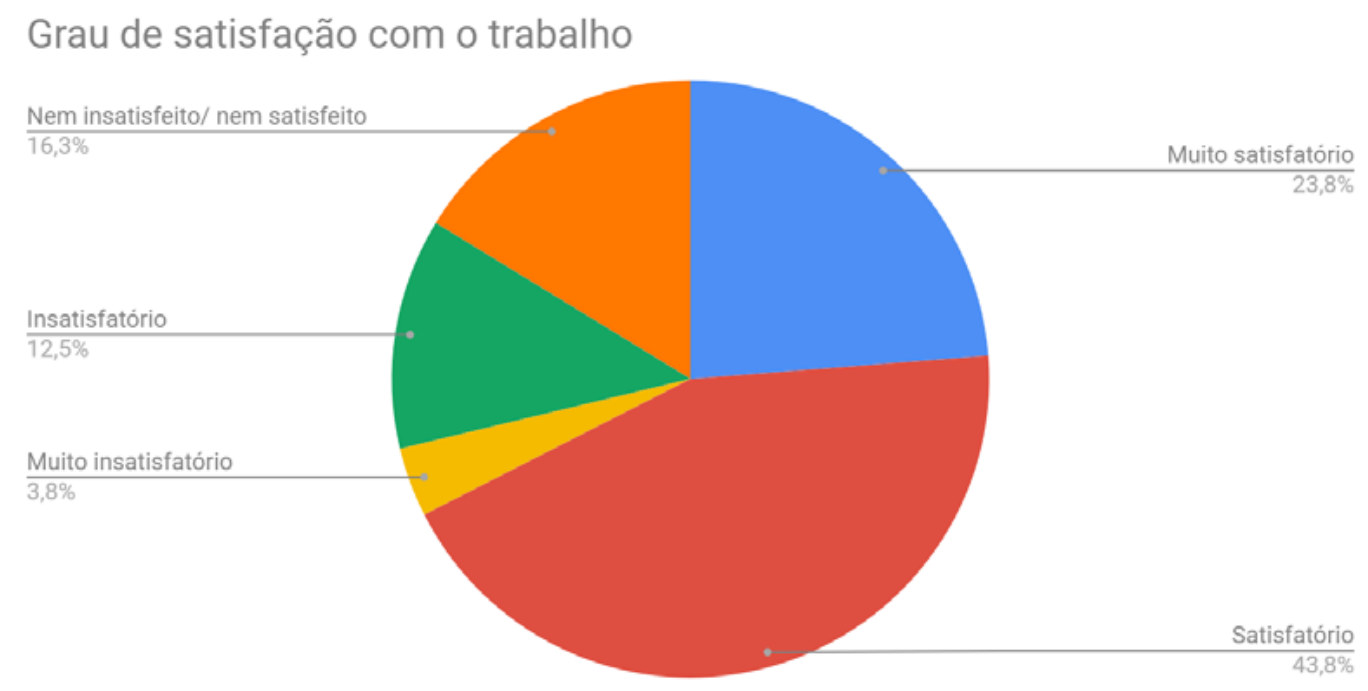

Média: 16 Desvio padrão: 12,08

Fonte: Elaborada pelas autoras 
Diante do exposto, de acordo com o gráfico 5, os dados desta pesquisa apontam que, entre os psicólogos investigados, prevalecem níveis altos de prazer e realização naquilo que produzem em termos laborais, uma vez que $43,8 \%$ dos egressos encontram-se satisfeitos com o trabalho atual, seguidos de 23,8\% muito satisfeitos. Por outro lado, 16,3\% não se sentem nem satisfeitos/nem insatisfeitos e 12,5 consideram-se insatisfeitos, seguidos por 3,8\% muito insatisfeitos ${ }^{7}$.

Malvezzi et al. [2010] encontraram resultados parecidos em sua pesquisa que investigou recémformados em psicologia no Brasil. Nela, os sentimentos em relação ao setor e à própria atuação revelaram alto índice de satisfação, o que sugere condição de profissionais adaptados e com grande parte das expectativas atendidas. Portanto, os dados aqui encontrados podem sinalizar que os egressos percebem o próprio trabalho como fértil porque contribui significativamente para resultados anteriormente planejado [Malvezzi et al. [2010]). Sendo assim, a satisfação se relaciona com a importância do trabalho para quem o realiza e também para a organização, pois esta não terá um bom desempenho se os colaboradores não estiverem envolvidos e realizados com o trabalho que ali desempenham [Veriguine, Basso \& Soares, 2014].

\section{Considerações finais}

Diante dos dados e reflexões aqui apresentados, percebe-se que os egressos do curso de Psicologia da Universidade Federal de Santa Catarina carregam elementos muito próximos dos dados nacionais (Bastos, 2010, Gondim, 2010, CFP, 1988), o que demonstra fortes evidências frente à formação recebida e principalmente à atuação dos psicólogos brasileiros.

Os profissionais investigados nesta pesquisa evidenciam nível elevado de empregabilidade, uma vez que dos 103 respondentes da pesquisa original, 78 [o que representa 75\% dos aqui analisados] encontram-se trabalhando em espaços que oferecem remuneração. 0 crescente assalariamento da profissão é marcado consequentemente pela diversidade de setores nos quais o psicólogo pode atuar. Relacionado a essa diversidade de setores de atuação, a pesquisa aqui realizada difere bastante das feitas há uma década em relação às atuações dos psicólogos.

Os dados desta pesquisa demonstram fortes mudanças na atuação profissional, pois a maioria dos profissionais que participaram desta pesquisa se encontram empregados no setor público. Isso pode ser explicado principalmente pelas políticas públicas no campo da saúde e assistência social, fortemente desenvolvidas nos anos recentes. Tais políticas podem ser visualizadas em ações vinculadas à psicologia social em espaços impulsionados pelo SUAS e também por formações complementares no nível de pós-graduação voltadas para atenção à saúde integral, direcionadas a uma clínica ampliada, transdisciplinar e muito perceptível na residência em hospitais, voltadas à saúde mental e atenção primária, assim como as políticas de formação em saúde pública, fortemente alavancadas pelo SUS [Mattos e Rodrigues, 2018].

$7 \quad$ Para fins de ilustração, a pesquisa inédita de Gusso et al. [2019] intitulada "Psicologia Organizacional e do Trabalho no Sul do Brasil: Características dos profissionais, da atuação e dos contextos de trabalho a ser publicada pela rPOT, aponta que os profissionais inscritos nos conselhos de psicologia da região sul do país possuem um comprometimento afetivo com o trabalho maior do que o instrumental e uma satisfação maior nos relacionamentos interpessoais e com a natureza do trabalho do que com a remuneração. Em nossa pesquisa, os níveis de envolvimento com o trabalho e comprometimento com a organização não foram investigados. 
É interessante observar o enriquecimento das práticas profissionais do psicólogo. Isso se manifesta na emergência e consolidação de novas áreas de conhecimento e de intervenção nas suas interfaces com outros campos do saber, como também no desenvolvimento e ampliação das possibilidades de atuação das áreas clássicas. Esses dados são recentes e quase não possuíam destaque na pesquisa nacional de trinta anos atrás [CFP, 1988], o que sugere novos horizontes para a atuação dos psicólogos. Outras atuações também apareceram nesta pesquisa e merecem destaque por extrapolar as atuações clássicas dos psicólogos. Dentre elas ganham destaque: psicologia do esporte, psicologia hospitalar, psicopedagogia e psicologia jurídica, as quais apontam para ampliação dos campos de trabalho, ainda que em índices menores.

A formação básica deve aprofundar as competências e habilidades que são centrais e indispensáveis para o psicólogo, dando a ele a capacidade de pensar as suas diferentes inserções e fazeres específicos. Porém, devido ao crescimento de novas áreas de extrema relevância, tornase necessário aos cursos de graduação incorporar conhecimentos sobre as áreas emergentes, incluindo a produção de pesquisas aplicadas e um posicionamento crítico em relação às práticas tradicionais [Bastos \& Gomide, 2010; Gondim, 2002].

Com a finalidade de possuir uma renda em patamares razoáveis e que seja suficiente para sustentar a si e, às vezes, dependentes, os dados também revelam que os profissionais atualmente já não atuam em diferentes frentes, pois o percentual de egressos analisados que conciliam atividades autônomas com o trabalho assalariado é de apenas 9,3\%. Além disso, o número de profissionais que atua apenas como autônomo também é baixo, 16,3\%. Sendo assim, os dados permitiram constatar que existe um grande número de psicólogos que possuem dedicação exclusiva a um único trabalho.

Isso demonstra algo diferente do que acontecia na década de 1980 e mostrado através dos dados do levantamento nacional realizado pelo CFP em 1988, quando mais de 60\% trabalhavam como autônomos. Difere também da pesquisa realizada em 2010 por Bastos e Gondim, quando $42,4 \%$ dos profissionais conciliavam as atividades de trabalho assalariado com as de trabalho autônomo. Tais dados demonstram que existe certa tendência de queda na conciliação de atividades e também do trabalho autônomo como principal alternativa de inserção profissional. Isso pode ser explicado pelo fato de muitas instituições públicas [possivelmente vinculadas a SUS e SUAS] estarem abrindo mais espaço para a contratação de psicólogos. Além disso, essas instituições necessitam de dedicação exclusiva por parte do profissional.

Destaca-se também que os profissionais analisados demonstram um alto nível de satisfação com seus atuais empregos. No questionário aqui utilizado, foi feita apenas uma pergunta sobre satisfação, por isso entende-se que para análises mais profundas sobre tal construto se faz necessário uma pesquisa mais ampla e focada nesse aspecto, de forma que possam inclusive utilizar escalas psicométricas específicas.

Por fim, reforça-se a importância de investigar como o contingente de egressos de psicólogos mais diverso - está sendo formado, onde está atuando e como pode contribuir, por meio de suas práticas profissionais, para aprimorar a Psicologia como ciência e profissão.

A realização de pesquisas com egressos é de extrema relevância, pois representa um importante mecanismo de autoavaliação por parte das instituições de educação superior. Por essa razão, o acompanhamento do percurso profissional dos egressos é uma das diretrizes que norteiam os 
Planos de Desenvolvimento Institucional das universidades, bem como é componente essencial do Sistema Nacional de Avaliação da Educação Superior [SINAES] do Ministério da Educação. Portanto, as ações de acompanhamento de egressos compõe um rol com objetivo de avaliar a eficácia da formação ofertada pelas IES.

A realização de estudos que permitam conhecer o tipo de desempenho e nível de empregabilidade que os ex-alunos estão tendo após obterem seus diplomas de graduação reflete também a formação que obtiveram na universidade.

Conclui-se, no entanto, que as percepções trazidas sobre a formação recebida e o levantamento sobre as trajetórias de carreira dos egressos aqui contemplados fornecem informações muito relevantes tanto para discutir mudanças curriculares, quanto para conhecer a realidade profissional, ainda que se caracterize como um estudo de caso sobre uma realidade profissional e institucional específica, o que restringe a possibilidade de generalizações. Contudo, ressalta-se que esta limitação paradoxalmente abre oportunidades de replicação em outras realidades, bem como de ampliação do estudo, tornando-o um mapeamento longitudinal.

\section{Referências}

Abbad, G. da S. \& Mourão, L. [2010]. Competências profissionais e estratégias de qualificação e requalificação. In: A.V. B. Bastos \& S. M. Gondim [Orgs.], O trabalho do psicólogo no Brasil: um exame à luz das categorias da psicologia organizacional e do trabalho (pp. 380-401]. Porto Alegre: Artmed.

Bastos, A. V. B. [1988] Áreas de atuação - em questão o nosso modelo profissional In: Conselho Federal de Psicologia. Quem é o psicólogo brasileiro? [pp. 163-193]. São Paulo: Edicon,

Bastos, A. V. B. \& Gomide, P. I.C. [2010]. O psicólogo brasileiro: sua atuação e formação profissional. In: O. H. Yamamoto \& A. L. F. Costa [Orgs.], Escritos sobre a profissão de psicólogo no Brasil [pp. 227-254]. Natal: EDUFRN.

Bastos, A. V. B.; Gondim, S. M. G. \& Borges-Andrade, J. E. [2010]. As mudanças no exercício profissional da psicologia no Brasil. $O$ que se alterou nas duas últimas décadas e 0 que vislumbramos a partir de agora? In: A. V. B. Bastos \& S. M. G. Gondim [Orgs.], 0 trabalho do psicólogo no Brasil: um exame à luz das categorias da psicologia organizacional e do trabalho [pp. 419-444]. Porto Alegre: Artmed.

Bastos, A. V. B.; Gondim, S. M. G. \& Borges-Andrade, J. E. [2010). O psicólogo brasileiro: sua atuação e formação profissional. O que mudou nas últimas décadas? In: O.H. Yamamoto, \& A.L.F. Costa [Orgs.], Escritos sobre a profissão de psicólogo no Brasil [pp. 255-270). Natal: EDUFRN.

Bendassolli, P. F. [2009]. Psicologia e trabalho: apropriações e significados. São Paulo: Cengage Learning.

Brasil. Ministério da Educação (2004). Diretrizes Curriculares Nacionais para os Cursos de Graduação em Psicologia. Resolução no 8, de 7 de maio de 2004. Diário Oficial da União. Brasília. 
Brasil. Ministério da Educação [2011]. Diretrizes Curriculares Nacionais para os Cursos de Graduação em Psicologia. Resolução no 15 de 15 de março de 2011. Diário Oficial da União. Brasília.

Callegari, M. M. [2001]. A inserção profissional de egressos universitários. Dissertação de Mestrado. Pontifícia Universidade Católica de Porto Alegre, Rio Grande do Sul. Disponível em http://xk.com.br/Insercao\%20de\%20Egressos\%20Univeritarios-\%2Odissertacao. pdf

Conselho Federal de Psicologia. [1992). Atribuições profissionais do psicólogo no Brasil. Disponivel em: https://site.cfp.org.br/wp-content/uploads/2008/08/atr prof psicologo.pdf

Conselho Federal de Psicologia. [1998]. Quem é o psicólogo brasileiro? São Paulo: Edicon

Dimenstein, M. A. (2000). A cultura profissional do psicólogo e o ideário individualista: implicações para a prática no campo da assistência pública à saúde. Estudos de Psicologia 5[1], 95121.

Gondim, S. M. G. [2002]. Perfil profissional e mercado de trabalho: Relação com a formação acadêmica pela perspectiva de estudantes universitários. Estudos de Psicologia, 7[2], 299-309. Disponível em: 10.1590/S1413-294X2002000200011

Instituto Brasileiro de Geografia e Estatística [IBGE]. [2018]. Pesquisa Nacional por Amostra de Domicílios Contínua (PNAD Contínua). Disponivel em: https://www.ibge.gov.br/ estatisticas-novoportal/sociais/educacao/9171-pesquisa-nacional-por-amostra-dedomicilios-continua-mensal.html?=\&t=destaques

Macêdo, K.B.; Heloani, R. \& Cassiolato, R. [2010]. O psicólogo como trabalhador assalariado setores de inserção, locais, atividades e condições de trabalho. In: A. V. B.Bastos \& S. M. G. Gondim [Orgs.], O trabalho do psicólogo no Brasil: um exame à luz das categorias da psicologia organizacional e do trabalho (pp. 131-150). Porto Alegre: Artmed.

Malvezzi, S. Souza, J. A. J. de. \& Zanelli, J. C. [2010]. Inserção no mercado de trabalho os psicólogos recém-formados. In: A. V. B. Bastos \& S. M. G. Gondim [Orgs.], 0 trabalho do psicólogo no Brasil: um exame à luz das categorias da psicologia organizacional e do trabalho [pp. 85-106]. Porto Alegre: Artmed.

Martinez, M., Paraguay, A. [2003]. Satisfação e saúde no trabalho: aspectos conceituais e metodológicos. Cadernos de Psicologia Social do Trabalho, 6, 59-78. Disponível em: https://www.revistas.usp.br/cpst/article/view/25851

Mattos, V. B.; Rodrigues, C. R. C. [2018]. Me formei em psicologia e agora? Considerações sobre o percurso profissional de egressos da UFSC. Anais do V Congresso Brasileiro Psicologia: Ciência e Profissão. São Paulo: UNINOVE.

Pasquali, L. [1998]. Condições de Trabalho do Psicólogo. In: Conselho Federal de Psicologia. Quem é o Psicólogo Brasileiro? [pp. 149-162]. São Paulo: Edicon. 
Sato, L. [2003]. Psicologia, saúde e trabalho: distintas construções dos objetos "trabalho" e "organizações". In Z. A. Trindade \& A. N. Andrade [Orgs.], Psicologia e saúde: um campo em construção [pp. 167-178]. São Paulo: Casa do Psicólogo.

Sato, L., Bernardo, M. H., \& Oliveira, F. [2008). Psicologia social do trabalho e cotidiano: a vivência de trabalhadores em diferentes contextos micropolíticos. Psicología para a América Latina, 15. Disponivel em: http://pepsic.bvsalud.org/scielo.php?script=sci arttext\&pid=S1870350X2008000400010

Veriguine, N. R., Basso, C., \& Soares, D. H. P. [2014]. Juventude e Perspectivas de Futuro: A Orientação Profissional no Programa Primeiro Emprego. Psicologia: Ciência e Profissão, 34[4], 1032-1044. https://dx.doi.org/10.1590/1982-370000902013

Yamamoto, O. H. \& Oliveira, I. F. [2010]. Política Social e Psicologia: uma trajetória de 25 anos. Psicologia: Teoria e Pesquisa, 26 (n. esp.), 9-24. Recuperado em 5 de setembro de 2018, da http://www.scielo.br/pdf/ptp/v26nspe/a02v26ns.pdf 